\title{
Dmrt1 mutation causes a male-to-female sex reversal after the sex determination by Dmy in the medaka
}

\author{
Haruo Masuyama • Masato Yamada • \\ Yasuhiro Kamei • Tomoko Fujiwara-Ishikawa • \\ Takeshi Todo • Yoshitaka Nagahama • \\ Masaru Matsuda
}

Published online: 21 December 2011

(C) Springer Science+Business Media B.V. 2011

\begin{abstract}
DMRT1, which is found in many vertebrates, exhibits testis-specific expression during the sexual differentiation period, suggesting a conserved function of DMRT1 in the testicular development of vertebrate gonads. However, functional analyses have been reported only in mammals. The current study focused on the Dmrt1 function in the teleost medaka, Oryzias latipes, which has an $\mathrm{XX}-\mathrm{XY}$ sex determination system. Although medaka sex is determined by
\end{abstract}

Responsible Editors: Tariq Ezaz and Jennifer Graves

H. Masuyama

United Graduate School of Agricultural Science,

Tokyo University of Agriculture and Technology,

Tokyo, Japan

H. Masuyama $\cdot$ M. Yamada $\cdot$ M. Matsuda $(\square)$

Center for Bioscience Research and Education,

Utsunomiya University,

350 Minemachi,

Utsunomiya, Tochigi 321-8505, Japan

e-mail: matsuda@cc.utsunomiya-u.ac.jp

Y. Kamei

Spectrography and Bioimaging Facility,

National Institute for Basic Biology,

Okazaki, Japan

T. Fujiwara-Ishikawa $\cdot$ T. Todo

Graduate School of Medicine, Osaka University,

Suita, Osaka, Japan

Y. Nagahama

Institute for Collaborative Relations, Ehime University,

Matsuyama, Japan the presence or absence of the Y chromosome-specific gene Dmy, we demonstrated that in one Dmrt1 mutant line, which was found by screening a gene-driven mutagenesis library, XY mutants developed into normal females and laid eggs. Histological analyses of this mutant revealed that the XY mutant gonads first developed into the normal testis type. However, the gonads transdifferentiated into the ovary type. The mutant phenotype could be rescued by transgenesis of the Dmrt1 genomic region. These results show that Dmrt1 is essential to maintain testis differentiation after Dmy-triggered male differentiation pathway.

Keywords Dmrt $1 \cdot$ medaka $\cdot$ sex reversal $\cdot$ gene-driven mutagenesis
Abbreviations
DM domain Doublesex ( $d s x)$ and male abnormality- 3 (mab-3) domain
ENU $\quad N$-ethyl- $N$-nitrosourea
DMRT1 Doublesex- and mab-3-related transcrip- tion factor 1
Dmy DM domain gene on the $\mathrm{Y}$ chromosome

\section{Introduction}

A DM domain gene, DMRT1 (doublesex- and mab3-related transcription factor 1), is required for human testis development (Raymond et al. 1999). In mice, 
Dmrt1 is expressed and required for both the germ cells and the Sertoli cells of the testes (Kim et al. 2007; Krentz et al. 2009; Matson et al. 2010). XY Dmrt1null mutant mice are born as males with testes, but these gonads later undergo abnormal differentiation (Raymond et al. 2000). The avian Z-linked DMRT1 is required for male sex determination in chickens (Smith et al. 2009). It is also involved in male development in other vertebrates including turtles, frogs, and teleost fish. The two sex-determining genes found in non-mammalian vertebrates, Dmy in medaka (Matsuda et al. 2002; Matsuda et al. 2007) and $D M-W$ in the African frog (Yoshimoto et al. 2008; Yoshimoto et al. 2010), are Dmrt1 homologues.

The teleost fish medaka Oryzias latipes has an $\mathrm{XX}-\mathrm{XY}$ male heterogametic sex determination system like mammals. The key factor that recruits the bipotential gonad with the XY chromosome constitution to the testicular pathway was identified as being a DM-domain-related gene on the Y chromosome, namely Dmy or dmrt1bY (Matsuda et al. 2002, Nanda et al. 2002). Dmy mRNA and protein are expressed specifically in the somatic cells surrounding germ cells in the early gonadal primordium before morphological sexual dimorphism is observed. The first morphological sexual dimorphism is observed in the proliferation of germ cells. Therefore, the number of germ cells is an important indicator for distinguishing a bipotential gonad recruitment to the testicular or ovarian pathway in the early developmental stages.

In an inbred Hd-rR strain, the sexual dimorphism of germ cells between the XX and XY gonads has been apparent at stage 38; subsequently, germ cells entered mitotic arrest in XY (Satoh and Egami 1972; Kobayashi et al. 2004), whereas they entered meiosis in XX after hatching. Dmy dysfunction leads to complete maleto-female sex reversal. XY fish of Dmy mutants or with low-level expression of Dmy have developed to egg-laying females (Matsuda et al. 2002; Shinomiya et al. 2004; Otake et al. 2006). Furthermore, the germ cells in the hatching stage of the embryos that have been blocked for Dmy translation by Dmyspecific grip-NA become female-like (Paul-Prasanth et al. 2006). These results suggest that XY gonads with blocked Dmy function commit to the female pathway.

In medaka, Dmrt1 is expressed in spermatogoniumsupporting cells, which is the same lineage cells expressing Dmy, after testicular differentiation (2030 days after hatching) (Kobayashi et al. 2004). In the case of medaka, high-temperature treatment or steroid hormone treatment can induce XX sex reversal (Yamamoto 1958; Sato et al. 2005; Hattori et al. 2007). This means that a gonad lacking Dmy can develop into testis and that Dmy is not necessary for testicular development. Dmy works as a natural inducer for normal testicular development. Dmrt1 appears to be a key gene in normal testicular development because in steroid hormone treatment-induced XX sexreversed testes, Dmrtl is expressed in the Sertoli cell lineage, similar to the expression of Dmy in XY testes (Kobayashi et al. 2004). High temperatures have also induced Dmrt1 expression in XX embryos (Hattori et al. 2007). However, it remains unclear whether Dmrt1 is necessary for testicular development in medaka.

To examine Dmrt1 function in the gonadal development of medaka, we screened an $N$-ethyl- $N$-nitrosourea (ENU)-based gene-driven mutagenesis library of medaka and found Dmrt1 mutants. In one Dmrt1 mutant line, $\mathrm{XY}$ individuals showed a male-to-female sex-reversal phenotype. The XY mutants developed into normal egg-laying females. Histological analyses of the developing gonads in the mutants revealed that by 10 days after hatching, the gonads of the XY mutants had already commenced development along the female pathway.

\section{Materials and methods}

\section{Biological specimen}

Two laboratory strains of medaka were used: the Cab strain and the inbred strain Hd-rR. The Cab strain was used to establish an ENU-based gene-driven mutagenesis library of medaka. The Cab strain is a sub-strain of the Carbio strain, which was established from fish obtained from Carolina Biological Supplies. Founder fish were repeatedly mutagenized with ENU and crossed with wild-type females, and the progeny were used to establish a permanently cryopreserved resource of 5,771 $F_{1}$ males (Taniguchi et al. 2006; Ishikawa et al. 2010). The Hd-rR strain was used for back-crossing and as a control in the gene expression analyses. 
Screening of Dmrt1 mutants in a gene-driven mutagenesis library

A gene-driven mutagenesis library has sets of frozen sperm and genomic DNA that were prepared from $5,771 \mathrm{~F}_{1}$ males. Polymerase chain reaction (PCR) products of the Dmrt1 exon 2 region of 5,600 stock DNAs within 5,771 were screened using high resolution melting (HRM) analysis and sequencing. PrimeSTAR $^{\circledR}$ Max DNA Polymerase (Takara Bio Inc., Shiga, Japan) was used as a DNA polymerase, and $0.83 \times$ LCGreen Plus (J. K. International, Tokyo, Japan) and $10 \%$ dimethylsulfoxide were added to the PCR reaction mix with the following primers: DM29f: 5'-CTG TAC AAG TGA ACC CCG CCT-3' and DM30r: 5'-GCG GTG TTT TGT TCG GTG-3'. PCR conditions were as follows: $5 \mathrm{~min}$ at $95^{\circ} \mathrm{C}$ followed by 30 cycles of $20 \mathrm{~s}$ at $96^{\circ} \mathrm{C}, 30 \mathrm{~s}$ at $55^{\circ} \mathrm{C}$, and $30 \mathrm{~s}$ at $72^{\circ} \mathrm{C}$, followed by $5 \mathrm{~min}$ at $72^{\circ} \mathrm{C}$; and a final denaturing and re-annealing step (one cycle of $94^{\circ} \mathrm{C}$ for $30 \mathrm{~s}$ followed by rapid cooling to $28^{\circ} \mathrm{C}$ ). The final step was included to redistribute DNA strands derived from mutant and wild-type alleles to maximize heteroduplex formation. After PCR, the plates were imaged in a 96-well LightScanner (Idaho Technology Inc., Salt Lake City, UT, USA) for HRM analyses as previously described (Taniguchi et al. 2006; Ishikawa et al. 2010).

The genomic DNAs showing melting curves that differed from those of the wild-type allele were selected as mutant candidates. The selected genomic DNA were purified using an ExoSAP-IT (General Electronics, Fairfield, CT, USA) and then used as a template for the sequencing reaction. The BigDye ${ }^{\circledR}$ Terminator v3.1 Cycle Sequencing Kit (Life Technologies Corporation, Carlsbad, CA, USA) with the primer 5'-GAA CCA CGG CTT CGT GTC T-3' was used for sequencing, which was performed using a 3100 genetic analyzer (Life Technologies Corporation).

\section{Genotyping}

The genetic sex of each specimen was determined using genomic PCR using the common primers for Dmrt1 and Dmy (Shinomiya et al. 2004). We used two methods to distinguish between the Dmrt1 mutant alleles and the wild-type alleles. The first method was direct sequencing of the PCR product. We amplified the Dmrtl genomic region using the DM29f and
DM30r primers, and the PCR products were purified using ExoSAP-IT (General Electronics). The sequencing methods are described above. The other method was genotyping the Dmrt1 ${ }^{C 53 R}$ mutation using the TaqMan ${ }^{\circledR}$ probe and the ABI PRISM 7500 (Life Technologies Corporation) with the Multiplex PCR Kit (QIAGEN, Hilden, Germany) using the DM29f and DM30r primers and the TaqMan ${ }^{\circledR}$ probe $5^{\prime}$-FAM-CTG CCG CTG CGC CA-TAMRA-3' $(2.0 \mu \mathrm{M})$, which was specific for the wild-type allele, and the VIC-TAMRA probe 5'-VIC-TGC CGC CGC GCC A-TAMRA-3' $(1.6 \mu \mathrm{M})$, which was specific for the mutant allele. PCR conditions were as follows: $15 \mathrm{~min}$ at $95^{\circ} \mathrm{C}$, followed by 40 cycles of $15 \mathrm{~s}$ at $95^{\circ} \mathrm{C}$ and $60 \mathrm{~s}$ at $60^{\circ} \mathrm{C}$.

\section{$\operatorname{Dmrt1}^{C 53 R}$ mating experiment}

The mating scheme for the Dmrt1 ${ }^{C 53 R}$ lines is shown in Fig. 1. The $G_{1}$ generation was produced by in vitro fertilization of normal eggs with frozen sperm. Further, the $G_{2}$ generation was produced by sib-mating between heterozygous individuals from the $\mathrm{G}_{1}$ generation. A homozygous XY mutant $(C 53 R / C 53 R)$ of the $G_{2}$ generation that developed as a female was crossed with an inbred Hd-rR male to produce the $\mathrm{G}_{3}$ generation. $X Y$ heterozygous individuals from the $\mathrm{G}_{3}$ generation were again back-crossed with Hd-rR. In the $\mathrm{G}_{4}$ generation, heterozygous males and females were sibmated to obtain the $\mathrm{G}_{5}$ generation.

An XX female with a genomic homozygous mutation $(C 53 R / C 53 R)$ was crossed with an Hd-rR XY male to obtain the $\mathrm{G}_{6}$ generation in which two types of mating were performed to obtain two distinct lines. The first line was used for back-crossing. A heterozygous $X Y$ of the $G_{6}$ generation was back-crossed with Hd-rR XX. Further, backcrosses were repeated two times. Heterozygous females of the $G_{9}$ generation were then mated with heterozygous males of the $G_{9}$ generation to obtain various combinations of Dmrt1 and sex chromosome types of $\mathrm{G}_{10}$ offspring for histological analyses 5 days after hatching. Homozygous $\mathrm{XX}$ from the resultant $\mathrm{G}_{10}$ generation were crossed with heterozygous XY to obtain many mutant individuals for gene expression and histological analyses.

The other line was used to obtain all XY progeny for a transgenic rescue experiment. To this end, we mated mutant $\mathrm{XY} \mathrm{G}_{5}$ females with heterozygous $\mathrm{XY}$ $\mathrm{G}_{6}$ males. Select heterozygous $(+/ C 53 R) \mathrm{YY}$ males 


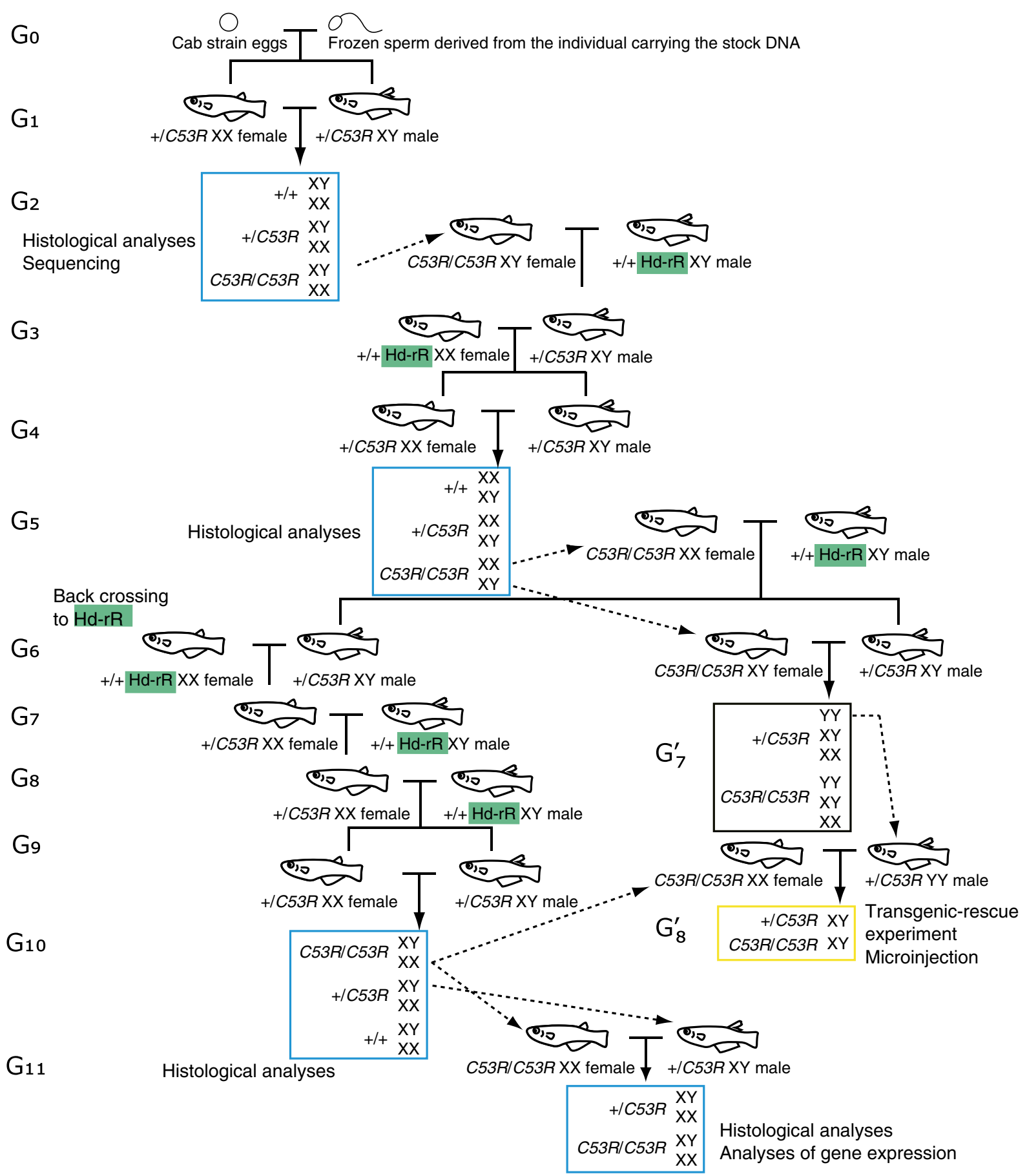

Fig. 1 Mating scheme. The mating scheme of $\operatorname{Dmrt1}{ }^{C 53 R}$ mutants. Details are provided in the "Materials and methods" section. The $\mathrm{G}_{2}, \mathrm{G}_{5}, \mathrm{G}_{10}$, and $\mathrm{G}_{11}$ generations were used for the

were crossed with homozygous $(C 53 R / C 53 R) \mathrm{XX}$ females derived from the $G_{10}$ generation of a back- histological analyses. The $\mathrm{G}_{11}$ generation was also used for gene expression analyses. The $\mathrm{G}_{8}^{\prime}$ generation was used for the transgenic rescue experiment

crossed line to obtain all of the XY eggs for the microinjection. 
Histological analyses of gonads

For histological analysis of the gonads and counting of the germ cells, fish were dissected into head and body segments 5, 10, 15, 20, and 30 days after hatching. Body segments containing gonads were fixed for $3 \mathrm{~h}$ in Bouin's reagent and then embedded in paraffin. On the other hand, each dissected head was used for DNA extraction and genotyping according to the protocol listed in the "Genotyping" section. Cross-sections were cut serially at 5- $\mu \mathrm{m}$ thicknesses and subjected to hematoxylin and eosin staining. All germ cells were counted for each fry at 5 days after hatching. After cell counting, the mean and standard error were calculated for each sex and the difference between the sexes was statistically evaluated using the paired $t$ test.

\section{RT-PCR}

To analyze testis- or ovary-specific gene expression, we extracted RNAs from Dmrt1 $^{C 53 R}$ and wild-type (Hd-rR) individuals. Whole bodies of each individuals at the day of hatching or the gonads of each individuals dissected at 30 days after hatching were put into a $1.5-\mathrm{mL}$ tube (ASSIST, Tokyo, Japan) with $300 \mu \mathrm{L}$ Buffer RLT (QIAGEN) and two zirconia beads with 3-mm diameters. They were homogenized in Micro Smash ${ }^{\mathrm{TM}}$ MS-100 (TOMY SEIKO CO., LTD, Tokyo, Japan) and then centrifuged for $3 \mathrm{~min}$ at $18,800 \times \mathrm{g}$ in a microcentrifuge. The supernatant was used for the RNA extraction, while the pellet was used for DNA extraction for genotyping. RNA was extracted using the RNeasy Mini Kit (QIAGEN), according to the manufacturer's protocol. Extracted RNA (200 ng of total RNA) was reverse-transcribed using a QuantiTect Reverse Transcription Kit (QIAGEN).

Dmy was amplified with the following primers (Otake et al. 2006): 5'-TGC CGG AAC CAC AGC TTG AAG ACC-3' and 5'-GCA TCT GCT GGT ACT GCT GGT AGT TG-3'. The PCR conditions were as follows: $5 \mathrm{~min}$ at $95^{\circ} \mathrm{C}$, followed by 45 cycles of $20 \mathrm{~s}$ at $96^{\circ} \mathrm{C}, 30 \mathrm{~s}$ at $65^{\circ} \mathrm{C}$, and $30 \mathrm{~s}$ at $72^{\circ} \mathrm{C}$, followed by $5 \mathrm{~min}$ at $72^{\circ} \mathrm{C}$. We analyzed the Dmy PCR products using the MultiNA Microchip Electrophoresis System (SHIMAZU, Kyoto, Japan). Quantitative gene expression analysis of the gonadal soma-derived factor $(G s d f)$ was performed using the ABI PRISM 7500 (Life Technologies Corporation) and QuantiTect SYBR Green PCR Kits (QIAGEN) following the protocols of Shibata et al. (2010). Dmy and Dmrt1 at 30 days after hatching were amplified using the following primers: 5'-CTG ACA TGA GCA AGG AGA
AGC AG-3' and 5'-CGC TTG TGG CCT TTC AGC-3'. PCR conditions were as follows: $5 \mathrm{~min}$ at $95^{\circ} \mathrm{C}$, followed by 30 cycles of $20 \mathrm{~s}$ at $96^{\circ} \mathrm{C}, 30 \mathrm{~s}$ at $65^{\circ} \mathrm{C}$, and $30 \mathrm{~s}$ at $72^{\circ} \mathrm{C}$, followed by $5 \mathrm{~min}$ at $72^{\circ} \mathrm{C}$. PCR products were analyzed by using 3\% agarose gel electrophoresis. Foxl2 and Cyp19a1 were amplified using the following primers: Foxl2, 5'-CGC CAC AGC AAA GCT CG-3' and 5'-TCG AGT GTC CAG TAA TTC CCC T-3'; and Cyp19a1, 5'-TGT GCT CAT TGT TGC TTG CAT C-3' and 5'-TAA TGC AAA ACA TTT GAT GAA TAA CAG TTC-3'. The PCR conditions were as follows: $5 \mathrm{~min}$ at $95^{\circ} \mathrm{C}$, followed by 30 cycles of $20 \mathrm{~s}$ at $96^{\circ} \mathrm{C}$, $30 \mathrm{~s}$ at $55^{\circ} \mathrm{C}$, and $30 \mathrm{~s}$ at $72^{\circ} \mathrm{C}$, followed by $5 \mathrm{~min}$ at $72^{\circ} \mathrm{C}$. The Foxl2 PCR products were electrophoresed on a $2 \%$ agarose gel, and the Cyp 19al PCR products were electrophoresed on a $1 \%$ agarose gel.

\section{Transgenesis}

The transgene constructs for generation of the Dmrt1 transgenic fish were prepared by sub-cloning the bacterial artificial chromosome (BAC) clone mCON075P1 containing the Dmrt1 genomic region. We replaced the original BAC clone vector $\mathrm{pBAC}$-lac backbone with the pCC1 vector (Epicentre Technologies, Madison, WI, USA). The pCC1 vector contains two types of replication origins. Under normal conditions, a single copy of this vector is present in a bacterium, whereas multiple copies are present in a bacterium in culture medium with induction solution. Green fluorescent protein (GFP) was used as a fluorescent reporter under the control of the medaka olvas promoter (Tanaka et al. 2001). We constructed a recombinant plasmid where vasa-GFP was inserted into the $\mathrm{pCC} 1$ vector in an earlier study (Otake et al. 2010). In the present study, we amplified this region using PCR and the following primer sets: 5'-TAG CGA TGA GCT CGG ACT TCC ATT GTT CA-3' and 5'-CGT AAT CAT GGT CAT AGC TGT TTC CTG TGT-3'. The PrimeSTAR ${ }^{\circledR}$ Max DNA Polymerase (TakaraBio Inc.) was used for the PCR reaction, and the conditions were as follows: $5 \mathrm{~min}$ at $96^{\circ} \mathrm{C}$, followed by 35 cycles of $10 \mathrm{~s}$ at $98^{\circ} \mathrm{C}, 5 \mathrm{~s}$ at $55^{\circ} \mathrm{C}$, and $65 \mathrm{~s}$ at $72^{\circ} \mathrm{C}$, followed by $3 \mathrm{~min}$ at $72^{\circ} \mathrm{C}$. We joined the BAC clone to the amplified fragment using a Red/ ET BAC Modification Kit (GeneBridge, Heidelberg, Germany), which enables the insertion of large sequences into BAC clones by homologous recombination.

TransforMax EPI300 electro-competent cells (Epicentre Technologies) were used for the transformation. 
Recombinant clones were cultured and induced by the addition of the CopyControl Induction Solution (Epicentre Technologies) to generate high plasmid copy numbers, according to the manufacturer's instructions. The clones were purified using $\mathrm{CsCl}$-ethidium bromide gradient ultracentrifugation. The BAC was injected into medaka single-cell-staged embryos of a cross between Dmrt $1^{C 53 R / C 53 R} \mathrm{XX}$ females and Dmrt1 ${ }^{+/ C 53 R}$ YY males. Fertilized eggs were collected within $40 \mathrm{~min}$ of spawning. The attaching filaments were scraped off the chorion onto a piece of paper. For microinjection of the recombinant BAC clone, we used DNA at $2.0 \mathrm{ng} / \mu \mathrm{L}$ in Yamamoto's solution. The injected eggs were incubated at $26^{\circ} \mathrm{C}$.

\section{Results}

Identification of a medaka Dmrt1 mutation

We screened 5,600 stock DNAs of a gene-driven mutagenesis medaka library. A 278-bp PCR fragment of the Dmrt1 gene containing a 5'-untranslated region
(47 bp), a translated region (207 bp), and an intron region ( $24 \mathrm{bp}$ ) was analyzed by HRM and sequencing. Four stock DNAs contained mutations in the translated region (Fig. 2a). Frozen sperm corresponding with the each stock DNA artificially fertilized normal eggs to obtain the $G_{1}$ generation. Heterozygous $G_{1}$ males and females were mated to obtain $G_{2}$ homozygous mutants.

We histologically analyzed gonads of these $G_{2}$ homozygous mutants (Table 1). In two mutant lines $\left(\right.$ Dmrt $1^{P 22 L}$ and Dmrt $1^{F 45 S}$ ), we could not find differences with normal gonads in either sex. In another mutant line (Dmrt1 $\left.{ }^{C 56 R}\right)$, the XY mutants had abnormal gonads. Most of them developed as males, but their testes contained a few oocytes, whereas a few of them developed female-like appearances and their gonads had many oocytes but no ovarian ducts and they did not lay eggs (Table 1).

In the other line (Dmrt1 $\left.{ }^{C 53 R}\right)$, both $\mathrm{XX}$ and $\mathrm{XY}$ mutants had abnormal gonads with a low number of germ cells. We assumed that the phenotypes were dependent on other mutated loci located near the
Fig. 2 Dmrtl mutations. a The mutation positions on the DM domain in Dmrtl exon 2. Four missense mutations were found: P22L, F35S, C53R, and C56R. Asterisks show the conserved cysteine and histidine residues thought to be important in the zinc-finger motif. The gray arrowhead shows the mutated position. The chromatogram of a wild-type individual showed one peak for thymine in amino acid 53 (b), that of the heterozygous individual $\left(\right.$ Dmrt $\left.1^{+/ C 53 R}\right)$ showed a double peak of cytosine and thymine (c), and that of the homozygous mutant $\left(\right.$ Dmrt1 $\left.1^{C 53 R / C 53 R}\right)$ showed one peak of cytosine (d)

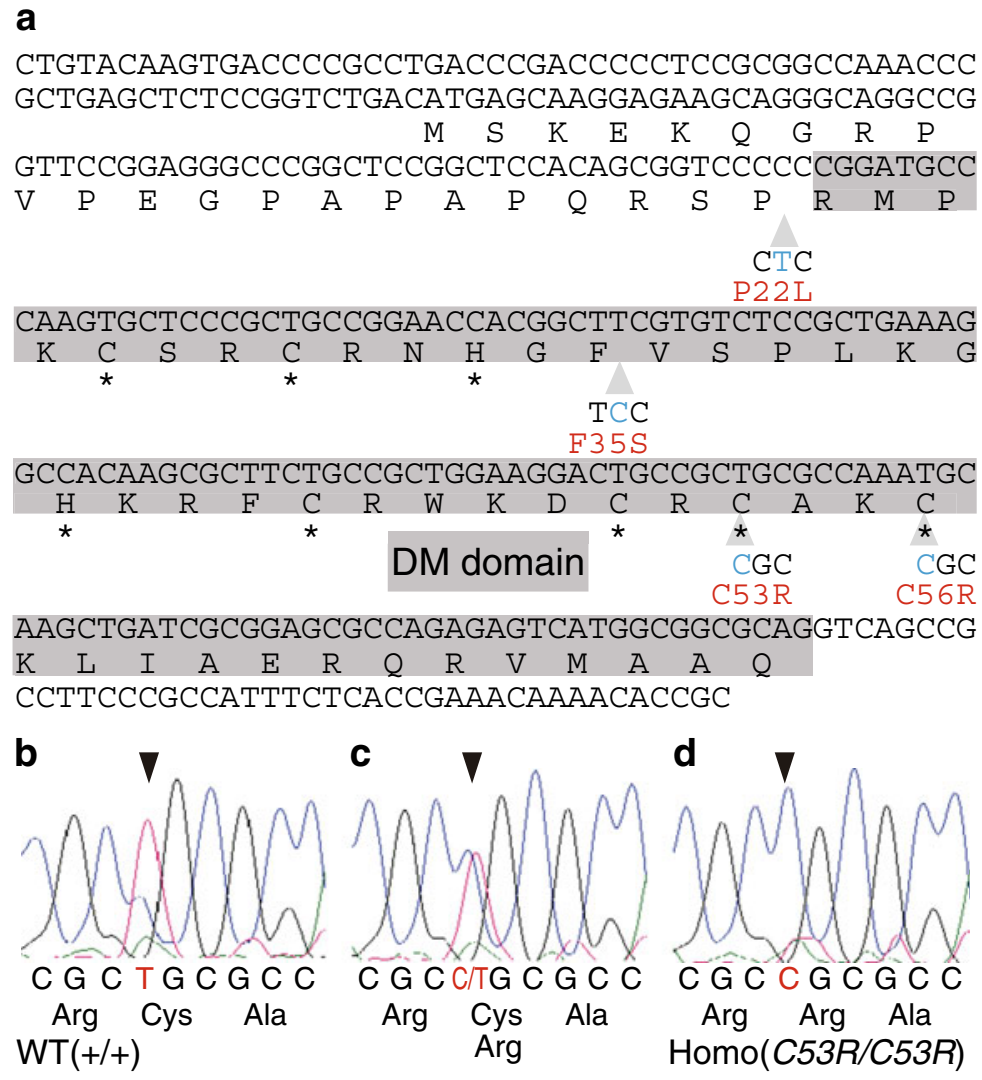


Table 1 Gonadal phenotypes in the $\mathrm{G}_{2}$ generation of Dmrt1 mutant lines at 30 days after hatching

\begin{tabular}{|c|c|c|c|c|}
\hline \multirow{2}{*}{$\begin{array}{l}\text { Sex } \\
\text { chromosome } \\
\text { type }\end{array}$} & \multirow{2}{*}{$\begin{array}{l}\text { Dmrt1 } \\
\text { alleles }\end{array}$} & \multirow{2}{*}{$\begin{array}{l}\text { Specimens } \\
(N)\end{array}$} & \multicolumn{2}{|c|}{ Gonad type } \\
\hline & & & Testis & Ovary \\
\hline XX & $P 22 L / P 22 L$ & 18 & 0 & 18 \\
\hline$X Y$ & $P 22 L / P 22 L$ & 9 & 9 & 0 \\
\hline $\mathrm{XX}$ & $F 45 S / F 45 S$ & 10 & 0 & 10 \\
\hline $\mathrm{XY}$ & $F 45 S / F 45 S$ & 10 & 10 & 0 \\
\hline $\mathrm{XX}$ & C56R/C56R & 5 & 0 & 5 \\
\hline XY & $C 56 R / C 56 R$ & 14 & $13^{\mathrm{a}}$ & 1 \\
\hline $\mathrm{XX}$ & C53R/C53R & $5^{\mathrm{b}}$ & - & - \\
\hline $\mathrm{XY}$ & $C 53 R / C 53 R$ & $5^{\mathrm{b}}$ & - & - \\
\hline
\end{tabular}

${ }^{a}$ Two of these testes contained a few oocytes

${ }^{\mathrm{b}}$ In both XX and XY, three gonads had no germ cells, whereas two had a few oocytes

Dmrt1. Therefore, we bred $>100$ offspring to obtain recombinants between the locus and Dmrt1. We then found that one XY homozygous mutant and two XX homozygous mutants developed into egg-laying females. The XY mutant was mated to the Hd-rR strain to obtain heterozygous individuals (Fig. 1). The heterozygous individuals were then saved for the next generation. We then histologically analyzed the gonads of the $\mathrm{G}_{5}$ generation obtained by mating heterozygous males with females. All of the $\mathrm{XY}$ homozygous mutants had ovaries. On the other hand, other combinations of sex chromosome type and Dmrt1 alleles had normal gonads depending on the sex chromosome type (Table 2). The Dmrt1 mutation was confirmed by genomic DNA sequencing (Fig. 2b-d).

Table 2 Gonadal phenotypes in the $\mathrm{G}_{5}$ generation of the Dmrt $1^{C 53 R}$ line at 30 days after hatching

\begin{tabular}{llll}
\hline $\begin{array}{l}\text { Sex } \\
\text { chromosome } \\
\text { type }\end{array}$ & $\begin{array}{l}\text { Dmrt1 } \\
\text { alleles }\end{array}$ & $\begin{array}{l}\text { Specimens } \\
(N)\end{array}$ & $\begin{array}{l}\text { Gonad } \\
\text { type }\end{array}$ \\
\hline $\mathrm{XX}$ & $+/+$ & 6 & Ovary \\
$\mathrm{XX}$ & $+/ C 53 R$ & 5 & Ovary \\
$\mathrm{XX}$ & $C 53 R / C 53 R$ & 5 & Ovary \\
$\mathrm{XY}$ & $+/+$ & 5 & Testis \\
$\mathrm{XY}$ & $+/ C 53 R$ & 7 & Testis \\
$\mathrm{XY}$ & $C 53 R / C 53 R$ & 7 & Ovary \\
\hline
\end{tabular}

Mutant phenotypes

The genetic males (XY) of the $\operatorname{Dmrt1}^{\text {C53R/C53R }}$ mutants developed into females. Therefore, to clarify when sex reversal occurs during gonadal differentiation, we histologically analyzed the gonadal phenotypes of the Dmrt1 ${ }^{C 53 R}$ mutants at 5, 10, 15, 20, and 30 days after hatching (Fig. 3, Table 3). At 5 days after hatching, we used the $\mathrm{G}_{10}$ generation obtained by sibmating the heterozygous $\left(D m r t 1^{+/ C 53 R}\right)$ individuals from the $\mathrm{G}_{9}$ generation, whereas at $10,15,20$, and 30 days after hatching, we used the $\mathrm{G}_{11}$ generation obtained by sib-mating the homozygous XX females $\left(\right.$ Dmrt1 $\left.{ }^{C 53 R / C 53 R}\right)$ with the Dmrt1 ${ }^{+/ C 53 R} \mathrm{XY}$ males from the $G_{10}$ generation. Before obtaining the $G_{9}$ generation, we back-crossed the homozygous $\left(\right.$ Dmrt1 $\left.1^{C 53 R / C 53 R}\right)$ or heterozygous $\left(\right.$ Dmrt1 $\left.1^{+/ C 53 R}\right)$ individuals six times with the Hd-rR strain to replace the genomic background with the inbred strain (Fig. 1). In a gene-driven mutagenesis library, it has been calculated that each sperm has approximately 2,300 ENUinduced mutations per genome (Taniguchi et al. 2006; Ishikawa et al. 2010). Furthermore, the mutagenesis library has been made using the Cab strain. We found some XX males in this strain.

Medaka germ cells become sexually dimorphic at stage 38, 2 days before hatching (Kobayashi et al. 2004). After hatching, the germ cells in the XY gonad (male type) enter mitotic arrest, whereas the germ cells in the XX gonad (female type) proliferate and enter meiosis (Satoh and Egami 1972). Therefore, testicular morphogenesis is distinct from ovarian morphogenesis at 5 days after hatching in normal medaka development. Germ cell numbers at 5 days after hatching differed significantly between the XY and XX individuals; however, there were no significant differences between germ cell numbers in the Dmrt1 ${ }^{C 53 R / C 53 R} \mathrm{XY}$ mutants and those in the wild-type $\mathrm{XY}$ individuals (Fig. 3a).

Histological analyses also demonstrated significant differences between the $\mathrm{XY}$ and $\mathrm{XX}$ gonads at 5 days after hatching (Table 3, Fig. 3b-e). XX gonads contained gonial germ cells and oocytes, whereas XY gonads contained only gonial germ cells. At 10 days after hatching, both heterozygous $\left(D m r t 1^{+/ C 53 R}\right)$ and mutant $\left(\right.$ Dmrt $\left.1^{C 53 R / C 53 R}\right) \mathrm{XX}$ gonads were similar to the ovary type seen in normal development. These gonads contained gonial germ cells and numerous oocytes at different developing stages in 
a

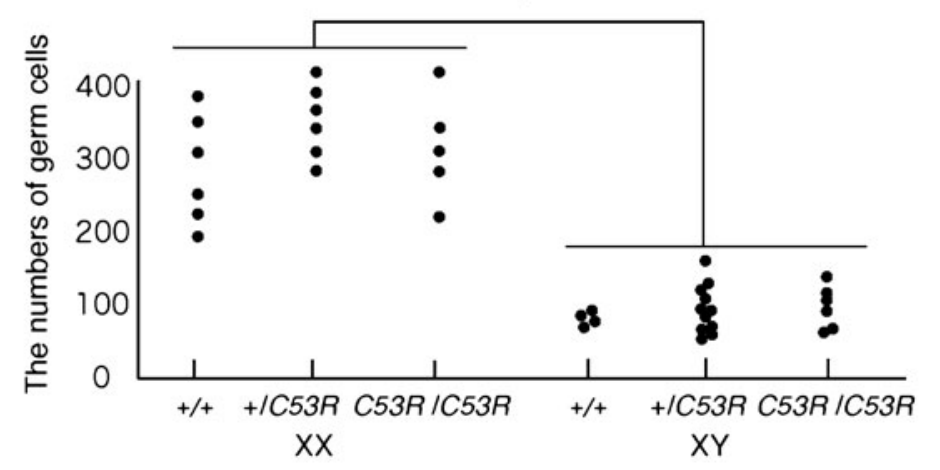

5 days after hatching

$x X$

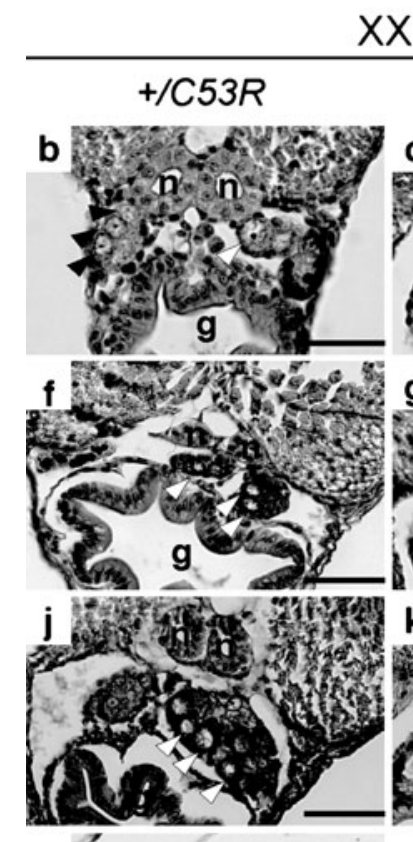

\section{C53R/C53R}

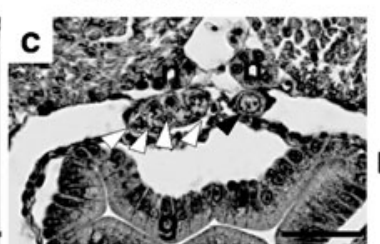

g mesis:
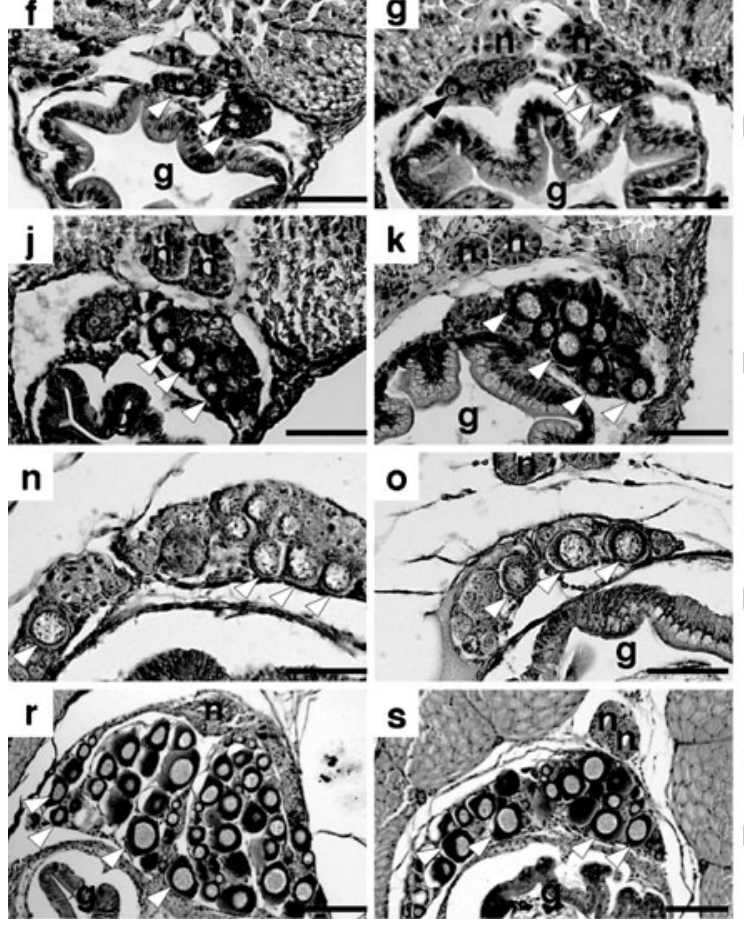

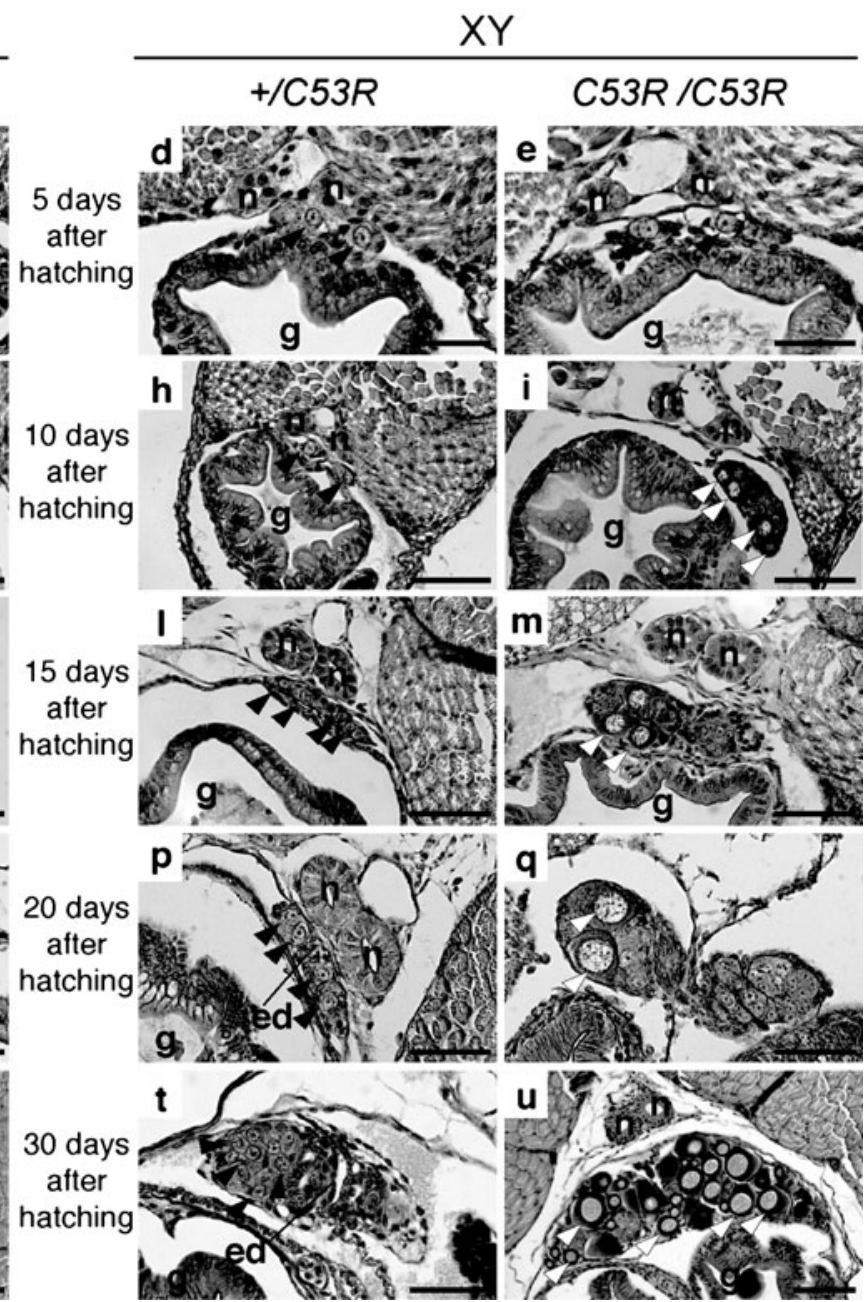


Fig. 3 Histological analyses of the Dmrt1 ${ }^{C 53 R}$ mutant gonads. The number of germ cells in the Dmrt1 ${ }^{C 53 R / C 53 R} \mathrm{XY}$ gonads resembled that in the wild-type $\left(\right.$ Dmrt $\left.^{+/+}\right) \mathrm{XY}$ gonads $\left({ }^{*} P<\right.$ $0.01)$ at 5 days after hatching (a). The gonads at $5(\mathbf{b}-\mathbf{e})$, $10(\mathbf{f}-\mathbf{i}), 15(\mathbf{j}-\mathbf{m}), 20(\mathbf{n}-\mathbf{q})$, and 30 days $(\mathbf{r}-\mathbf{u})$ after hatching. The Dmrt1 ${ }^{+/ C 53 R}$ and Dmrt1 ${ }^{C 53 R / C 53 R} \mathrm{XX}$ gonads were the ovary type. The $D m r t 1^{+/ C 53 R} \mathrm{XY}$ gonads were the testis type; however, the Dmrt1 ${ }^{C 53 R / C 53 R} \mathrm{XY}$ gonads were the testis type at 5 days after hatching but were the ovary type and contained oocytes at 10, 15, 20, and 30 days after hatching. Black arrowheads indicate gonial-type germ cells; white arrowheads indicate various sizes of oocytes at the diplotene stage. $n$ nephric duct, $g$ gut, $e d$ efferent duct. Scale bar $=40 \mu \mathrm{m}$

normally developing ovaries filled with many oocytes at various stages of the diplotene stage, with oocytes at the zygotene and pachytene stages and gonial germ cells (Fig. 3j-k, m-o, q-s, u). On the other hand, the Dmrt1 $1^{+/ C 53 R} \mathrm{XY}$ gonads, which contained gonial germ cells and somatic cells, were similar to the testis type seen in normal development (Fig. 31, $\mathrm{p}, \mathrm{t}$ ). The somatic cells at 20 and 30 days after hatching formed testis-specific structures-efferent ducts. The Dmrt1 ${ }^{C 53 R / C 53 R} \mathrm{XY}$ gonads appeared to have fewer oocytes than did the XX gonads.

All homozygous XY mutants developed into egglaying females, while all heterozygous XY mutants developed into males. By mating these females with males, we could obtain YY individuals containing heterozygous and homozygous mutants in the Dmrt1 locus. The heterozygous YY individuals developed into male with male secondary sexual characteristics and produced sperm, whereas homozygous YY mutants did not have male secondary sexual characteristics and did not lay eggs. The gonads of homozygous YY mutants contained a few developing oocytes without ovarian cavity (data not shown).

Next, we analyzed the gene expression profile of testis- and ovary-specific genes on the day of hatching and 30 days after hatching (Fig. 4). On the day of hatching, the expression of the testis-specific genes $D m y$ and $G s d f$ was examined by reverse transcriptase (RT)-PCR and real-time quantitative RT-PCR. All
$\mathrm{XY}$ individuals expressed Dmy, but $\mathrm{XX}$ individuals did not (Fig. 4a). The relative mRNA expression level of $G s d f$ in the Dmrt ${ }^{C 53 R / C 53 R} \mathrm{XY}$ embryos was lower than that in the wild-type XY embryos but higher than that in all of the XX embryos (Fig. 4b).

At 30 days after hatching, the expression of the testis-specific genes Dmy and Dmrt1 and the ovaryspecific genes Foxl2 and Cyp 19a1 were also examined by RT-PCR. The Dmrt1 expression was detected in all samples (Fig. 4c). Wild-type $\left(\right.$ Dmrt $\left.1^{+/+}\right) \mathrm{XX}$ and mutant (Dmrt1 $\left.{ }^{C 53 R / C 53 R}\right) \mathrm{XY}$ gonads showed lesser expression than did the wild-type $\mathrm{XY}$ and heterozygous $\left(D m r t 1^{+/ C 53 R}\right) \mathrm{XY}$ gonads. Conversely, Dmy expression was detected in only XY gonads. Moreover, the $D m r t 1^{C 53 R / C 53 R} \mathrm{XY}$ gonads showed higher expression than did the other wild-type and Dmrt1 ${ }^{+/ C 53 R} \mathrm{XY}$ gonads. The wild-type XX gonads expressed both the ovary-specific genes, whereas the expression of these genes was undetectable in the wild-type XY gonads and in the $D m r t 1^{+/ C 53 R} \mathrm{XY}$ gonads (Fig. 4d, e). However, the Dmrt1 ${ }^{C 53 R / C 53 R} \mathrm{XY}$ gonads expressed both the ovary-specific genes (Fig. 4d, e).

\section{Phenotype of mutant carrying Dmrt1 transgene}

To determine whether the sex reversal of the $D m r t 1^{C 53 R / C 53 R} \mathrm{XY}$ mutants was caused by the Dmrt $1^{C 53 R}$ mutation, we inserted an exogenous Dmrt1 gene regulated by its own promoter into the genome of Dmrt $1^{C 53 R / C 53 R} \mathrm{XY}$ mutant embryos. To this end, we constructed a recombinant BAC clone containing the medaka Dmrtl genomic region derived from an inbred Hd-rR strain and vasa-GFP driven by a medaka germ cell-specific olvas promoter (Tanaka et al. 2001) as a fluorescent reporter gene (Fig. 5a). The BAC was injected into medaka single-cell-staged embryos of a cross between $\operatorname{Dmrt1}^{+/ C 53 R} \mathrm{YY}$ males and Dmrt1 ${ }^{C 53 R / C 53 R}$ XX females. The Dmrt1 $1^{+/ C 53 R} \mathrm{YY}$ male was obtained by crossing $D m r t 1^{+/ C 53 R} \mathrm{XY}$ males with $D m r t 1^{C 53 R / C 53 R} \mathrm{XY}$ females (Fig. 5b). We obtained
Table 3 Numbers of specimens measured using histological analyses and the phenotypes at $5,10,15,20$, and 30 days after hatching

Ova ovary-type gonads, Tes testis-type gonads

\begin{tabular}{lllllll}
\hline Sex chromosome type & Dmrt1 & 5 & 10 & 15 & 20 & 30 \\
\hline $\mathrm{XX}$ & $+/ C 53 R$ & 6 Ova & 5 Ova & 5 Ova & 5 Ova & 5 Ova \\
$\mathrm{XX}$ & $C 53 R / C 53 R$ & 5 Ova & 5 Ova & 5 Ova & 5 Ova & 5 Ova \\
$\mathrm{XY}$ & $+/ C 53 R$ & 11 Tes & 5 Tes & 5 Tes & 5 Tes & 5 Tes \\
$\mathrm{XY}$ & $C 53 R / C 53 R$ & 6 Tes & 5 Ova & 5 Ova & 5 Ova & 5 Ova \\
\hline
\end{tabular}




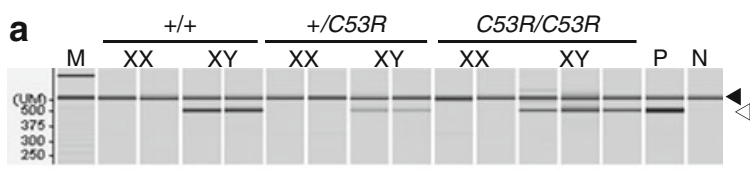

b

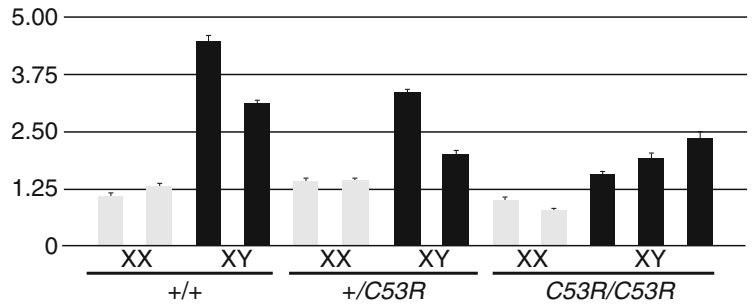

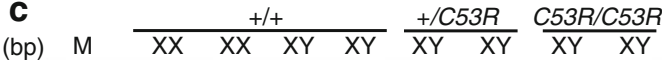
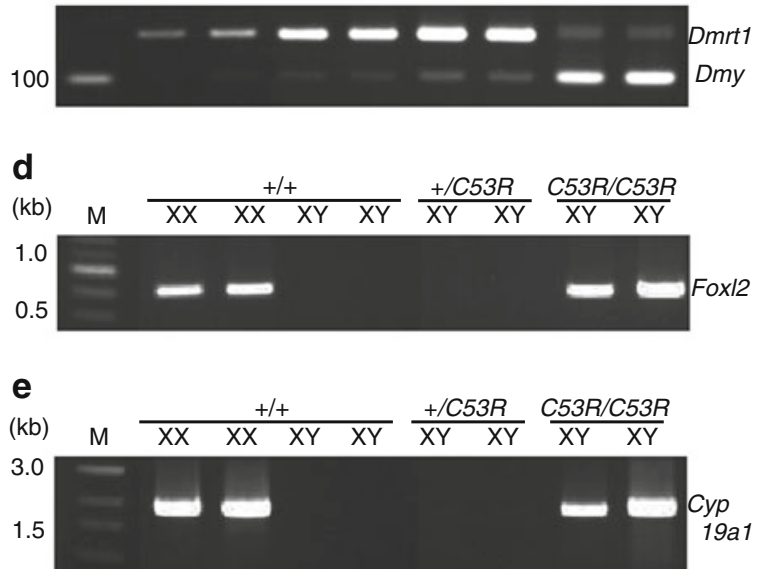

Fig. 4 Gene expression analyses of the Dmrt1 ${ }^{C 53 R}$ mutants. a Expression of Dmy immediately after embryo hatching. The XY embryos expressed Dmy immediately after hatching, but the XX embryos did not. P (positive control), Hd-rR adult testis; N (negative control), distilled water. The black arrowhead shows the upper marker, which is used to correct the moving distance of DNA fragments with lower marker, which is the lower position (not shown), in the MultiNA system. The white arrowhead indicates the positions of the Dmy fragments. b The relative mRNA expression of $G s d f$ in the Dmrt1 ${ }^{C 53 R / C 53 R} \mathrm{XY}$ embryos immediately after hatching was lower than that in the wild-type (Hd-rR) XY embryos but higher than that in all the XX embryos. c Dmrt1 and Dmy expression in the gonads at 30 days after hatching. Dmrt1 expression was detected in all samples. However, wild-type (Hd-rR) XX and Dmrt1 ${ }^{C 53 R / C 53 R}$ $\mathrm{XY}$ gonads showed lesser expression than did the wild-type (Hd-rR) XY and Dmrt1 $1^{+/ C 53 R} \mathrm{XY}$ gonads. Conversely, Dmy expression was detected only in $\mathrm{XY}$ gonads. However, the Dmrt1 $1^{C 53 R / C 53 R} \mathrm{XY}$ mutant gonad showed stronger expression than did the other wild-type and Dmrt1 ${ }^{+/ C 53 R} \mathrm{XY}$ gonads. The expression of Foxl2 (d) and Cyp19al (e). At 30 days after hatching, the PCR products of ovary-specific genes were detected in the Dmrt1 ${ }^{C 53 R / C 53 R} \mathrm{XY}$ gonads and wild-type XX gonads but not in the $D m r t 1^{+/ C 53 R} \mathrm{XY}$ or wild-type XY gonads one germline-transmitting founder in the $\mathrm{F}_{0}$ generation, a $D m r t 1^{+/ C 53 R} \mathrm{XY}$ male. The $\mathrm{F}_{0} \mathrm{XY}$ was crossed with a Dmrt1 ${ }^{C 53 R / C 53 R} \mathrm{XX}$ female to obtain the $\mathrm{F}_{1}$ generation. In the $\mathrm{F}_{1}$ generation, $10 \mathrm{XY}$ individuals and six $\mathrm{XX}$ individuals inherited the exogenous Dmrt1.

Genotyping of the Dmrt1 allele in the $\mathrm{F}_{1}$ individuals could not be achieved because the copy number of exogenous wild-type Dmrtl inherited in $\mathrm{F}_{1}$ was significantly higher than that of endogenous Dmrtl, and hid the original Dmrtl allele in the genotyping assay in each $F_{1}$. Genotypes of all $F_{1}$ were judged as being wild type. Therefore, we established an $\mathrm{F}_{2}$ genotyping method in which we mated each of the $10 \mathrm{~F}_{1} \mathrm{XY}$ individuals with $\mathrm{Dmrt1}^{\mathrm{C53R/C53R}} \mathrm{XX}$ females to obtain the next generation $\left(\mathrm{F}_{2}\right)$. Since we could judge transgene inheritance using the GFP fluorescent from vasaGFP in the $F_{2}$, we could select $F_{2}$ individuals lacking the transgene to genotype for the Dmrt1 allele. Based on the $F_{2}$ genotypes, we could judge the parental genotypes. Since Dmrt1 ${ }^{C 53 R / C 53 R}$ females were used for female parents, when we could not find ${ }_{D m r t 1}^{+/ C 53 R} \mathrm{~F}_{2}$ in the offspring, the $\mathrm{F}_{1}$ parental male was deemed $\mathrm{Dmrt1}^{\mathrm{C53R} / \mathrm{C53R}}$. Nine of $10 \mathrm{~F}_{1} \mathrm{XY}$ individuals developed male secondary sex characteristics and were identified as being fertile.

The results from $\mathrm{F}_{2}$ genotyping revealed that one of the nine $\mathrm{F}_{1} \mathrm{XY}$ individuals was homozygous mutant $\operatorname{Dmrt1}^{C 53 R / C 53 R}$ and the remaining eight were $D_{m r t 1} 1^{+/ C 53 R}$ (Table 4). Furthermore, of the $F_{2}$ individuals that were obtained from crossing the $\mathrm{F}_{1} \operatorname{Dmrt1}^{\text {C53R/C53R }} \mathrm{XY}$ males $\left(\mathrm{F}_{1} \mathrm{ID}=9\right)$ with Dmrt1 ${ }^{C 53 R / C 53 R} \mathrm{XX}$ females, no $\mathrm{XY}$ individuals carrying the transgene developed as females and 10 of 17 developed as males (Table 5). On the other hand, all $\mathrm{XX}$ individuals carrying the transgene were developed as females.

\section{Discussion}

In this study, we identified and characterized a missense mutant of the medaka Dmrtl gene $D m r t 1^{C 53 R}$. The heterozygous $\left(D m r t 1^{+/ C 53 R}\right) \mathrm{XY}$ gonads developed into testes, whereas the homozygous $\left(D m r t 1^{C 53 R / C 53 R}\right) \mathrm{XY}$ gonads developed into ovaries. Furthermore, the Dmrt1 ${ }^{C 53 R / C 53 R} \mathrm{XY}$ mutants were fertile, indicating that they underwent a complete male-to-female sex reversal. The influence of the Dmrt1 ${ }^{C 53 R}$ mutation on the $\mathrm{XY}$ individuals 
Fig. 5 Transgenic rescue experiment of Dmrt1 ${ }^{C 53 R / C 53 R} \mathrm{XY}$ mutants. The structure of the bacterial artificial chromosome (BAC) clone containing the Dmrt1 genomic region, which encompasses $35 \mathrm{~kb}$ of a six-exon region, $80 \mathrm{~kb}$ of the upstream region, and $30 \mathrm{~kb}$ of the downstream region (a). A pCC1 vector fragment encoding vasa-green fluorescent protein and a kanamycin resistance gene was replaced in the pBAClac vector region of the BAC construct using a homologous recombination system. The Dmrt1 ${ }^{\text {C53R/C53R }}$ $\mathrm{XY}$ mutants carrying the transgene developed into males. The Dmrt1 ${ }^{\text {C53R/C53R }}$ $\mathrm{XY}$ mutants have female secondary sexual characteristics (b), whereas the Dmrt $1^{\text {C53R/C53R }} \mathrm{XY}$ mutants carrying the transgene are male (c) with a testis (d and e). Scale bar $=100 \mu \mathrm{m}$
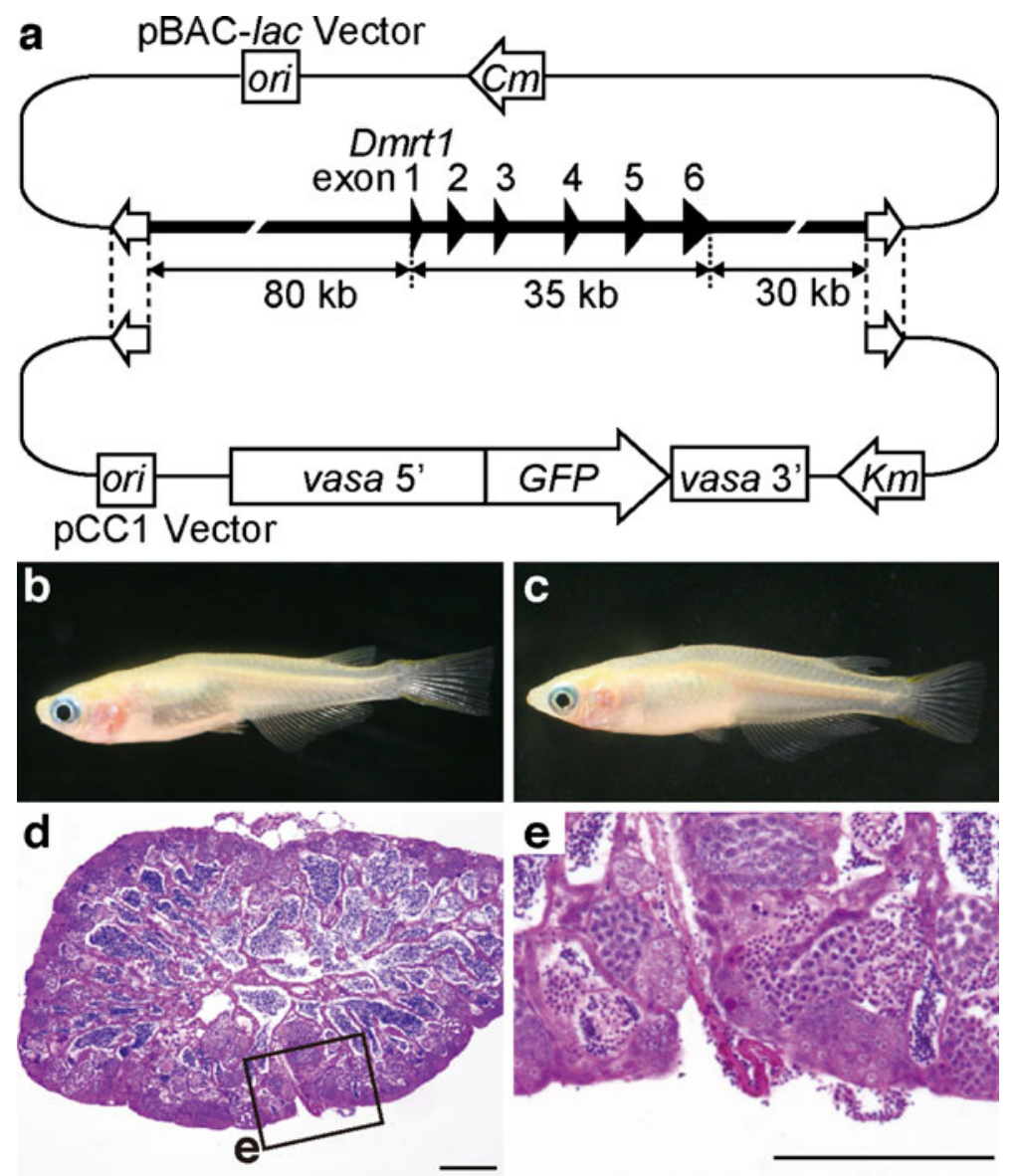

Table 4 Genotyping of the $F_{1}$ males in the transgenic rescue experiment

\begin{tabular}{|c|c|c|c|}
\hline \multirow[t]{2}{*}{$\mathrm{F}_{1}$ male } & \multicolumn{2}{|c|}{$\mathrm{F}_{2}$ individuals $(N)^{\mathrm{a}}$} & \multirow[t]{2}{*}{$\mathrm{F}_{1}$ male genotype } \\
\hline & $C 53 R / C 53 R$ & $+/ C 53 R$ & \\
\hline 1 & 3 & 5 & $+/ C 53 R$ \\
\hline 2 & 4 & 4 & $+/ C 53 R$ \\
\hline 3 & 6 & 2 & $+/ C 53 R$ \\
\hline 4 & 3 & 5 & $+/ C 53 R$ \\
\hline 5 & 2 & 6 & $+/ C 53 R$ \\
\hline 6 & 6 & 2 & $+/ C 53 R$ \\
\hline 7 & 5 & 3 & $+/ C 53 R$ \\
\hline 8 & 12 & 4 & $+/ C 53 R$ \\
\hline 9 & 24 & 0 & C53R/C53R \\
\hline 10 & 0 & 0 & - \\
\hline
\end{tabular}

${ }^{\mathrm{a}} \mathrm{F}_{2}$ individuals that did not inherit the transgene were obtained by crossing $\mathrm{F}_{1}$ males with mutant $D m r t 1^{C 53 R / C 53 R}$ females shows that Dmrt1 is necessary for testicular development. To determine whether the sex reversal of the Dmrt1 ${ }^{C 53 R / C 53 R} \mathrm{XY}$ mutants was caused by disrupted Dmrt1 function, we inserted an exogenous Dmrt1 gene into the $\operatorname{Dmrt1}^{C 53 R / C 53 R} \mathrm{XY}$ mutants. The resulting Dmrt1 ${ }^{C 53 R / C 53 R} \mathrm{XY}$ "male" carrying the exogenous Dmrt1 was fertile, revealing that Dmrt1 is indispensable for testicular development in medaka. This function is the same as that of mouse Dmrtl (Raymond et al. 2000) and chicken DMRT1 (Smith et al. 2009), suggesting the functional conservation of $D M R T 1$ among vertebrates.

Table 5 Secondary sexual characteristics of $F_{2}$ progeny that inherited the transgene in the transgenic rescue experiment

\begin{tabular}{llll}
\hline Sex chromosome type & Male & Female & Not judged \\
\hline $\mathrm{XX}$ & 0 & 6 & - \\
$\mathrm{XY}$ & 10 & - & $7^{\mathrm{a}}$
\end{tabular}

${ }^{a}$ One of these gonads contained oocytes, whereas the others were immature and could not be decided on testes or ovaries 
Steroid hormone or high temperature treatments have induced complete sex reversals. These facts have indicated that an XY bipotential gonad can develop into not only a testis but also a complete ovary in medaka (Yamamoto 1958; Sato et al. 2005; Hattori et al. 2007). Although our XY Dmrt1 mutant finally developed into a female, in the early stage before 5 days after hatching, the germ cell number was similar to that of wild-type XY gonads, and the expression patterns of the testis-specific genes were also more similar to that of the wild-type $X Y$ gonads than the $\mathrm{XX}$ gonads. We found only gonial germ cells in XY mutant gonads at 5 days after hatching, whereas we found oocytes at the diplotene stage in mutant XY gonads that were similar to XX gonads at 10 days after hatching. These observations demonstrate that prior to 5 days after hatching, XY mutant gonads develop along the testis pathway. Conversely, by 10 days after hatching, the gonads of the Dmrt1 ${ }^{C 53 R / C 53 R} \mathrm{XY}$ mutants have already commenced development along the female pathway. This delayed commencement of ovarian development may cause the low number of oocytes in $\mathrm{XY}$ mutant gonads compared to those in $\mathrm{XX}$ gonads.

An XY bipotential gonad develops into an ovary when fertilized XY eggs are immersed in estrogencontaining water. However, this estrogen treatment does not affect Dmy expression (Scholz et al. 2003; Suzuki et al. 2005). In these estrogen-treated XY gonads, significant increases of germ cell numbers have not been observed before hatching and at 1 and 2 days after hatching, whereas they have been confirmed at 3 days after hatching (Suzuki et al. 2005). On the other hand, Dmy dysfunction also leads XY bipotential gonads to the female pathway by blocking Dmy translation and mutations (Shinomiya et al. 2004; Otake et al. 2006; Paul-Prasanth et al. 2006). The germ cell numbers of these $\mathrm{XY}$ gonads are similar to those of XX gonads before hatching (Paul-Prasanth et al. 2006). Therefore, the transdifferentiation process from testis to ovary induced by Dmrt1 mutation differs from that by estrogen treatment and that by Dmy dysfunction. The timing of transdifferentiation in Dmrt1-mutant $\mathrm{XY}$ gonads is later than that in estrogen-treated $\mathrm{XY}$ gonads.

At hatching, Dmy mRNA expression in heterozygous XY embryos was a little lower than those in wildtype and mutant XY embryos (Fig. 4a). However, the germ cell numbers of the heterozygous $\mathrm{XY}$ embryos were not affected at 5 days after hatching (Fig. 3a), suggesting that Dmy function was not affected at the mRNA level. Heterozygous Dmrt1 status may affect Dmy promoter activity.

Mutant XY gonads at 30 days after hatching were comparable to complete ovaries containing many oocytes at different stages of development and expressing ovary-specific genes (Figs. $3 \mathrm{u}$ and $4 d$, e). However, the testis-specific gene Dmy was expressed at a level that was markedly higher than those of wildtype or heterozygous XY gonads, whereas expression of the testis-specific gene Dmrtl was very low (Fig. 4c). This is not unusual because Dmy expression has been found in the follicle layer of estrogeninduced adult XY ovaries (Suzuki et al. 2005), suggesting that the Dmy acts on somatic cells surrounding germ cells regardless of testis or ovary status.

Three genes are known to be expressed with sexual dimorphism in somatic cells surrounding germ cells of $\mathrm{XY}$ gonads in medaka. The first gene is Dmy, whose mRNA has been detected in XY gonads at stage 36 by using in situ hybridization (Kobayashi et al. 2004). Expression of the second gene, Gsdf, at stage 37 is higher in XY gonads than in XX gonads (Shibata et al. 2010). The third gene is Dmrt1. However, in situ hybridization has not been able to distinguish between Dmy and Dmrtl because the hybridization probe for Dmy mRNA hybridizes both Dmy and Dmrt1 mRNAs due to their high similarity ( $93 \%$ at the nucleic acid level) (Kobayashi et al. 2004). Although these $\mathrm{XY}$-specific genes are expressed in somatic cells, morphological dimorphisms of somatic cells have not been found between XX and XY gonads.

Morphological sexual dimorphisms are first found in germ cells at this early developmental stage (Satoh and Egami 1972; Kobayashi et al. 2004). The sexual dimorphism in the number of germ cells results in two distinct types of germ cell proliferation in gonadal sex differentiation: type I proliferation contributes to a linear increase in the number of germ cells in XY gonads, whereas type II proliferation sustains an exponential increase in germ cells in XX gonads, which lack the Dmy gene. In XX gonads, germ cells enter meiosis following type II proliferation (Saito et al. 2007). Since Dmy dysfunction causes female-type germ cell proliferation (Paul-Prasanth et al. 2006), it is assumed that a Dmy function is to inhibit type II proliferation of germ cells until 5 days after hatching. On the other hand, germ cells in Dmrt1-mutant XY 
gonads, which have the Dmy gene, enter the female pathway at 10 days after hatching. Since the germ cells of normally developing XY gonads in this period are mitotically arrested, one of the presumed Dmrt 1 functions is also restraining type II proliferation of these germ cells.

Acknowledgments We acknowledge Drs. M. Iigo and B. Prasanth for their critical suggestions. This work was supported in part by Grants-in-Aid from the Narishige Zoological Science Award, The Novartis Foundation (Japan) for the Promotion of Science, and MEXT Japan.

\section{References}

Hattori RS, Gould RJ, Fujioka T, Saito T, Kurita J, Strüssmann CA, Yokota M, Watanabe S (2007) Temperature-dependent sex determination in Hd-rR medaka Oryzias latipes: gender sensitivity, thermal threshold, critical period, and DMRT1 expression profile. Sexual Dev 1:138-146

Ishikawa T, Kamei Y, Otozai S, Kim J, Sato A, Kuwahara Y, Tanaka M, Deguchi $T$, Inohara $H$, Tsujimura $T$, Todo $T$ (2010) High-resolution melting curve analysis for rapid detection of mutations in a Medaka TILLING library. BMC Mol Biol 11:70

Kim S, Bardwell VJ, Zarkower D (2007) Cell type-autonomous and non-autonomous requirements for Dmrt1 in postnatal testis differentiation. Dev Biol 307:314-327

Kobayashi T, Matsuda M, Kajiura-Kobayashi H, Susuki A, Saito N, Nakamoto M, Shibata N, Nagahama Y (2004) Two DM domain genes, DMY and DMRT1, involved in testicular differentiation and development in the medaka, Oryzias latipes. Dev Dyn 231:518-526

Krentz AD, Murphy MW, Kim S, Cook MS, Capel B, Zhu R, Matin A, Sarver AL, Parker KL, Griswold MD, Looijenga LH, Bardwell VJ, Zarkower D (2009) The DM domain protein DMRT1 is a dose-sensitive regulator of fetal germ cell proliferation and pluripotency. Proc Natl Acad Sci USA 106:22323-22328

Matson CK, Murphy MW, Griswold MD, Yoshida S, Bardwell VJ, Zarkower D (2010) The mammalian doublesex homo$\log D M R T 1$ is a transcriptional gatekeeper that controls the mitosis versus meiosis decision in male germ cells. Dev Cell 19:612-624

Matsuda M, Nagahama Y, Shinomiya A, Sato T, Matsuda C, Kobayashi T, Morrey CE, Shibata N, Asakawa S, Shimizu N, Hori H, Hamaguchi S, Sakaizumi M (2002) DMY is a Y-specific DM-domain gene required for male development in the medaka fish. Nature 417:559-563

Matsuda M, Shinomiya A, Kinoshita M, Suzuki A, Kobayashi T, Paul-Prasanth B, Lau EL, Hamaguchi S, Sakaizumi M, Nagahama Y (2007) DMY gene induces male development in genetically female (XX) medaka fish. Proc Natl Acad Sci USA 104:3865-3870

Nanda I, Kondo M, Hornung U, Asakawa S, Winkler C, Shimizu A, Shan Z, Haaf T, Shimizu N, Shima A, Schmid M, Schartl M (2002) A duplicated copy of DMRT1 in the sex- determining region of the Y chromosome of the medaka, Oryzias latipes. Proceedings of the National Academy of Sciences of the United States of America 99:11778-11783

Otake H, Shinomiya A, Matsuda M, Hamaguchi S, Sakaizumi M (2006) Wild-derived XY sex-reversal mutants in the medaka, Oryzias latipes. Genetics 173:2083-2090

Otake H, Masuyama H, Mashima Y, Shinomiya A, Myosho T, Nagahama Y, Matsuda M, Hamaguchi S, Sakaizumi M (2010) Heritable artificial sex chromosomes in the medaka, Oryzias latipes. Heredity 105:247-256

Paul-Prasanth B, Matsuda M, Lau EL, Suzuki A, Sakai F, Kobayashi T, Nagahama Y (2006) Knock-down of DMY initiates female pathway in the genetic male medaka, Oryzias latipes. Biochem Biophys Res Commun 351:815-819

Raymond CS, Parker ED, Kettlewell JR, Brown LG, Page DC, Kusz K, Jaruzelska J, Reinberg Y, Flejter WL, Bardwell VJ, Hirsch B, Zarkower D (1999) A region of human chromosome $9 \mathrm{p}$ required for testis development contains two genes related to known sexual regulators. Hum Mol Genet 8:989-996

Raymond CS, Murphy MW, O’Sullivan MG, Bardwell VJ, Zarkower D (2000) Dmrt1, a gene related to worm and fly sexual regulators, is required for mammalian testis differentiation. Genes Dev 14:2587-2595

Saito D, Morinaga C, Aoki Y, Nakamura S, Mitani H, Furutani-Seiki M, Kondoh H, Tanaka M (2007) Proliferation of germ cells during gonadal sex differentiation in medaka: insights from germ cell-depleted mutant zenzai. Dev Biol 310:280-290

Sato T, Endo T, Yamahira K, Hamaguchi S, Sakaizumi M (2005) Induction of female-to-male sex reversal by high temperature treatment in medaka, Oryzias latipes. Zool Sci 22:985-988

Satoh N, Egami N (1972) Sex differentiation of germ cells in the teleost, Oryzias latipes, during normal embryonic development. J Embryol Exp Morphol 28:385-395

Scholz S, Rösler S, Schäffer M, Hornung U, Schartl M, Gutzeit HO (2003) Hormonal induction and stability of monosex populations in the medaka (Oryzias latipes): expression of sex-specific marker genes. Biol Reprod 69:673-678

Shibata Y, Paul-Prasanth B, Suzuki A, Usami T, Nakamoto M, Matsuda M, Nagahama Y (2010) Expression of gonadal soma derived factor $(G S D F)$ is spatially and temporally correlated with early testicular differentiation in medaka. Gene Expr Patterns 10:283-289

Shinomiya A, Otake H, Togashi KI, Hamaguchi S, Sakaizumi M (2004) Field survey of sex-reversals in the medaka, Oryzias latipes: genotypic sexing of wild populations. Zool Sci 21:613-619

Smith CA, Roeszler KN, Ohnesorg T, Cummins DM, Farlie PG, Doran TJ, Sinclair AH (2009) The avian Z-linked gene $D M R T 1$ is required for male sex determination in the chicken. Nature 461:267-271

Suzuki A, Nakamoto M, Kato Y, Shibata N (2005) Effects of estradiol-17 $\beta$ on germ cell proliferation and $D M Y$ expression during early sexual differentiation of the medaka Oryzias latipes. Zool Sci 22:791-796

Tanaka M, Kinoshita M, Kobayashi D, Nagahama Y (2001) Establishment of medaka (Oryzias latipes) transgenic lines with the expression of green fluorescent protein fluorescence exclusively in germ cells: a useful model to monitor 
germ cells in a live vertebrate. Proc Natl Acad Sci USA 98:2544-2549

Taniguchi Y, Takeda S, Furutani-Seiki M, Kamei Y, Todo T, Sasado T, Deguchi T, Kondoh H, Mudde J, Yamazoe M, Hidaka M, Mitani H, Toyoda A, Sakaki Y, Plasterk RH, Cuppen E (2006) Generation of medaka gene knockout models by target-selected mutagenesis. Genome Biol 7: R116

Yamamoto T (1958) Artificial induction of functional sexreversal in genotypic females of the medaka (Oryzias latipes). J Exp Zool 137:227-263
Yoshimoto S, Okada E, Umemoto H, Tamura K, Uno Y, Nishida-Umehara C, Matsuda Y, Takamatsu N, Shiba $\mathrm{T}$, Ito M (2008) A W-linked DM-domain gene, $D M-W$, participates in primary ovary development in Xenopus laevis. Proc Natl Acad Sci USA 105:24692474

Yoshimoto S, Ikeda N, Izutsu Y, Shiba T, Takamatsu N, Ito M (2010) Opposite roles of DMRT1 and its W-linked paralogue, $D M-W$, in sexual dimorphism of Xenopus laevis: implications of a ZZ/ZW-type sex-determining system. Development 137:2519-2526 